\title{
Darwinismo em James: A Função da Consciência na Evolução ${ }^{1}$
}

\author{
Renato Rodrigues Kinouchi ${ }^{2}$ \\ Universidade Federal do $A B C$
}

\begin{abstract}
RESUMO - O darwinismo desempenha um papel central na psicologia jamesiana. Com efeito, os conceitos de variação e seleção fornecem uma maneira de escapar tanto do determinismo fisiológico quanto do determinismo sociológico. Ademais, o darwinismo permite a James mostrar a função e a eficácia causal da consciência na evolução dos seres humanos. Este trabalho pretende, por meio de uma análise histórico-conceitual, discutir tais questões que informam a primeira psicologia científica feita nos Estados Unidos.
\end{abstract}

Palavras-chave: darwinismo; evolução; variação e seleção; consciência; William James.

\section{Darwinism in James: The Function of Consciousness in the Evolution}

\begin{abstract}
Darwinism plays a major role in jamesian psychology. In fact, the concepts of variation and selection provide a way to escape from both physiological and sociological determinism. Moreover, Darwinism allows James to show the function and the causal efficacy of consciousness in the evolution of human beings. By means of an historical and conceptual analysis, we discuss these questions which inform the first scientific psychology developed in the United States.
\end{abstract}

Key words: darwinism; evolution; variation and selection; consciousness; William James.

Credita-se ao psicólogo alemão Wilhelm Wundt (18321920) o mérito de haver sido o fundador da Psicologia como disciplina científica e autônoma. A nova abordagem, muito mais empírica do que a praticada até então, tinha como ponto inovador o uso do método experimental de pesquisa. Um dos cientistas que naquela época também se aventurava na aplicação do método experimental era o norte-americano William James (1842-1910), médico e professor na Universidade de Harvard. Fato interessante, embora pouco divulgado, é que James, em 1875, quando era instrutor de Fisiologia, já havia estabelecido informalmente um pequeno laboratório de Fisiologia aplicada à Psicologia, onde realizava demonstrações pedagógicas para seus alunos. Ou seja, no último quarto do século XIX, a Psicologia Experimental já se encontrava incipiente na América, com pouca defasagem em relação à Europa. Diga-se de passagem que James não tinha especial vocação para trabalho laboratorial - preferia dedicar-se ao trabalho teórico - mas indubitavelmente se mostrava atualizado com o rumo tomado do outro lado do Atlântico.

Muito embora não almejasse, para si, sucesso extraordinário na pesquisa de laboratório, sem sombra de dúvida de-

1 O autor agradece à FAPESP auxílio por meio de bolsa de Pós-doutoramento junto ao Projeto Temático "Estudos de Filosofia e História da Ciência". Este trabalho contém partes da tese de doutoramento "Consciência não-linear: de William James aos Sistemas dinâmicos", defendida junto ao Departamento de Filosofia e Metodologia das Ciências, da Universidade Federal de São Carlos.

2 Endereço: Rua Catequese, 242, Jardim, Santo André, SP, Brasil 09090400.E-mail:kinouchi@scientiaestudia.org.br veu-se a James o mérito de haver escrito um dos primeiros manuais para ensino de Psicologia. De fato, no ano de 1878, fora convidado a escrever um livro para ser utilizado por estudantes de graduação. O plano inicial era que o trabalho estivesse pronto em dois anos, mas o livro ganhou uma tal dimensão que só foi definitivamente terminado em 1890, 12 anos após a assinatura do contrato. Só então o editor Henry Holtz pôde publicar a obra Os Princípios de Psicologia (James, 1890/1983b), originalmente composta em dois volumes, que ganhou adeptos, bem como críticos, ao longo de todo o século XX.

James trazia de sua formação em medicina a idéia de que seres humanos são sistemas biológicos que procuram sobreviver no meio ambiente. E, para que um sistema dessa natureza sobreviva, seus diversos órgãos precisam executar funções vitais de maneira coordenada. O coração tem a função de bombear sangue para os tecidos, o pulmão tem a função de proceder às trocas gasosas, e assim por diante. $\mathrm{O}$ cérebro, por sua vez, coordena tais funções, e ainda tem a característica adicional, e peculiar, de ser o órgão onde se dá a função da cognição. Note-se, portanto, que James naturalizava os processos cognitivos sem reduzi-los ao substrato material (Harrison, 2004), e isso o levava a considerar as relações funcionais entre o organismo e o meio no qual se encontra. Aparece aqui o que se convenciona chamar de funcionalismo jamesiano. Para um estudo específico sobre a naturalização da consciência proposta por James, consultar Flanagan (1997).

Em paralelo ao funcionalismo, uma outra concepção, inovadora para a época, informava a psicologia preconizada por James: a saber, o evolucionismo de Charles Darwin 


\section{R. R. Kinouchi}

(1809-1882). Mas o psicólogo aplicava o darwinismo de maneira peculiar, analisando tanto fenômenos psicológicos como socioculturais. Esses dois usos do darwinismo foram motivados por questões com o mesmo foco, mas em níveis distintos: o repúdio a ambas, tanto teorias deterministas na fisiologia quanto na sociologia. No primeiro caso, James utiliza o darwinismo para criticar teorias mecanicistas na fisiologia. No segundo, critica uma teoria evolucionária determinista defendida pelo filósofo britânico Herbert Spencer (1820-1903). Ambas as questões foram tratadas quase no mesmo período (entre 1878 e 1880), sendo difícil precisar em qual delas James trabalhou primeiro. O mais provável é que ele as tenha enfrentado concomitantemente. Julgamos mais acertado explorar primeiro a faceta psicofisiológica do problema, pois se espera que isso facilite a posterior compreensão do tema sociológico mais amplo.

\section{O Mecanicismo Fisiológico e o Problema da Eficá- cia Causal da Consciência}

Em 1878, James apresenta seu argumento darwinista em favor da autonomia e eficiência causal da consciência sobre os processos fisiológicos cerebrais - o qual se encontra no artigo "Are we automatas?" (James, 1878/1983a). Tal argumento chegou à sua versão definitiva no Princípios de Psicologia (1890/1983b), no capítulo intitulado "Teoria do Autômato". Para nossos propósitos, utilizaremos a versão contida no Princípios, pois ali o argumento se apresenta de forma completa e explícita ${ }^{3}$.

Mas antes de examinar essa questão, vale assinalar algumas considerações gerais que irão facilitar nossa tarefa. Em especial, é notório que James, ao escrever, se esmerava em questões estilísticas, imprimindo ao seu texto características bem peculiares. Uma delas era escrever em primeira pessoa, dando aos seus escritos uma entonação similar àquela exigida em apresentações orais. Ou seja, conquanto o texto jamesiano seja adequado à norma culta, sua estrutura dialógica lhe confere fluidez e dinamicidade. Mas é exatamente por isso que não se deve sempre lê-lo literalmente, pois, às vezes, aquilo que é exposto no início de um capítulo vem a ser rechaçado no final. Assim, é habitual que James exponha os pontos de vista de seus adversários, de modo que o leitor desavisado chega a crer que ele está defendendo tal ponto de vista. Mas isso é parte da estratégia de dar voz ao adversário.

James inicia o capítulo "Teoria do autômato" disposto a analisar os pressupostos da neurofisiologia de sua época. Partindo unicamente dessa perspectiva, indaga sobre o que seria preciso aceitar como premissa básica para que se pudesse explicar o fenômeno da inteligência. Antes de tudo, se adotada a abordagem neurofisiológica, é preciso aceitar que cada uma de nossas ações inteligentes está ligada a pro-

3 Há uma tradução parcial desse capítulo em Herrnstein e Boring (1971). Mas todas as citações e passagens utilizadas neste artigo foram traduzidas pelo autor deste presente artigo cessos neurais que lhes são simultâneos e subjacentes - de modo que para cada ato deve corresponder um processo cerebral. E, por mais complexa que possa ser uma cadeia de ações, a cadeia de processos cerebrais subjacentes deve se apresentar com o mesmo grau de complexidade. Caso contrário, o fisiologista teria que admitir uma ação inteligente sem correspondência com um evento neural. Portanto, é preciso adotar um princípio de continuidade entre as ações inteligentes e o aparato neural que as produz.

Com efeito, James (1890/1983b) enfatiza que até mesmo nas estruturas nervosas mais simples e inferiores, tais como a medula espinhal e o sistema simpático, encontramse respostas comportamentais que em grande medida podem sem consideradas como dotadas de inteligência, mesmo que sejam ações inconscientes, no vago sentido de não-percebidas - por exemplo, reflexos motores que nos mantêm na posição "em pé", sem que nos apercebamos disso. Mas cabe então a pergunta: "Já que ações de alguma complexidade são ocasionadas por um mero mecanismo, por que as ações ainda mais complexas não seriam resultado de um mecanismo mais refinado?" (p. 133). Com essa indagação James levanta um forte argumento da teoria fisiológica mecanicista, como se, digamos, proporcionasse munição ao adversário. Nas palavras de James:

\begin{abstract}
A concepção de ação reflexa é sem dúvida uma das maiores conquistas da teoria fisiológica; por que não radicalizá-la? Por que não dizer que assim como a medula espinhal é uma máquina com poucos reflexos, os hemisférios cerebrais são uma máquina com muitos, e que nisso está toda a diferença? (p. 133).
\end{abstract}

Ou seja, aceitando também o princípio de continuida$d e$ entre as estruturas mais simples (medula espinhal) e as mais complexas (córtex cerebral) é possível supor que as diferenças entre as respectivas ações se devam apenas às quantidades de reflexos de cada uma das estruturas mencionadas. Porém, ao efetuar a radicalização do argumento mecanicista da ação reflexa, James indaga:

\begin{abstract}
Mas nessa visão qual seria a função da consciência ela mesma? Função mecânica ela não poderia ter. Os órgãos dos sentidos despertariam as células cerebrais (...) uma seqüência racional e ordenada, até que a ação ocorresse; e então, a última vibração cerebral iria descarregar na direção motora [downward into the motor tracts]. Isso seria uma completa cadeia de ocorrências autônomas, e onde quer que estivesse a consciência, ela seria apenas um epifenômeno, um espectador inerte, uma espécie de espuma, aura ou melodia (p.133).
\end{abstract}

Isso significa que a radicalização da teoria mecanicista da ação reflexa não prevê a possibilidade de eficácia causal da consciência sobre a fisiologia cerebral (o chamado epifenomenalismo). Incorre-se em uma noção de consciência passiva e fantasmagórica, que simplesmente acompanha e justapõe-se à cadeia de eventos cerebrais, mas que se mostra incapaz de influenciá-los (cf. Kinouchi 2004). 
A seguir, James discorre sobre a origem das concepções filosóficas que negam a eficácia causal da consciência sobre a série de eventos cerebrais. No entender dele, deve-se creditar a Descartes (1649/1999) a concepção de um aparelho neural auto-suficiente, capaz de executar atos aparentemente inteligentes. Muito embora o filósofo francês tenha feito claramente a distinção entre o ser humano - possuidor de uma alma racional - e os animais e autômatos - que não teriam racionalidade stricto sensu - sua perspectiva está na base do pensamento mecanicista dos fisiologistas da segunda metade do século XIX. Ocorre que esses últimos deram o passo final na direção do princípio de continuidade, e de uma vez por todas defenderam que nem mesmo no homem a consciência exerce influência significativa ${ }^{4}$. Assim sendo, não se nega a existência da série de eventos mentais, no entanto, concebe-os apenas como um epifenômeno simultâneo aos processos mecânicos cerebrais. Todavia, tal epifenômeno é tão capaz de influenciar a série de eventos cerebrais quanto a fumaça expelida por uma locomotiva a vapor pode alterar o rumo do comboio; ou seja, em nada.

No subtítulo "Razões a Favor da Teoria" são discutidas razões usualmente levantadas pelos defensores da teoria do autômato consciente. Neste ponto é preciso que o leitor mantenha-se atento, pois, caso contrário, ele pode ser levado a crer que James realmente defendia a validade dessa teoria. Porém essas razões a favor são na verdade o preâmbulo da crítica propriamente dita.

Duas são as virtudes da abordagem fisiológica mecanicista: simplicidade e coerência. O princípio de continuidade garante que se os processos fisiológicos elementares das estruturas mais simples (tal como os reflexos da medula espinhal) são inteligentes, então os processos superiores claramente racionais devem ser a conseqüência natural da complexidade das estruturas cerebrais superiores do córtex. Dessa forma, os defensores do ponto de vista fisiológico mecanicista transformam uma questão qualitativa em uma de natureza quantitativa. Seria apenas uma questão de quantidades de reflexos em cada uma das estruturas (poucos para a medula espinhal, e muitíssimos para o córtex cerebral). Essa transformação do qualitativo em termos quantitativos assemelha-se aos procedimentos utilizados nas chamadas ciências exatas, e os cientistas da época buscavam incessantemente analogias dessa natureza.

Contudo, James (1890/1983b) aponta que no próprio âmbito da Fisiologia se origina uma questão ambígua. Dois pesquisadores da época, Pflüger e Lewes (citado por James, 1890/1983b), utilizaram o mesmo princípio de continuidade e propuseram um contra-argumento do seguinte tipo: "Já que ações complexas e inteligentes são acompanhadas de consciência num nível superior (córtex), então as ações simples e inteligentes da medula espinhal podem ser acom-

4 Interessante notar que as premissas mecanicistas do behaviorismo watsoniano já se encontravam colocadas e que, de alguma maneira, o conceito de reflexo condicionado também foi uma forma de explicar o comportamento seguindo um princípio de continuidade entre o simples (um reflexo isolado) e o complexo (cadeias de reflexos condicionados). panhadas pela invisivel presença de uma consciência em nível inferior" p. (137). Ora, o princípio de continuidade deve permanecer válido tanto quando é aplicado ascensionalmente, quanto descensionalmente. Mas quando aplicado do complexo para o simples (descensionalmente), traz consigo dificuldades imensas, tais como postular "a invisível presença de uma consciência em nível inferior" (p. 137), no âmbito das ações reflexas da medula espinhal.

James assinala que um impasse desse tipo mostra motivações estéticas e ideológicas que podem impregnar a pesquisa científica. A atitude dos fisiologistas mecanicistas, frente ao impasse imposto pelo uso do princípio de continuidade descensionalmente, consistia em simplesmente negar eficácia causal à consciência, esquivando-se do árduo trabalho de pesquisá-la nos processos automáticos inferiores, e por fim generalizando essa prática até mesmo para os processos superiores. Assim a consciência passa a ficar fora do campo da ciência, e quem se atreva a desrespeitar o interdito, é sumariamente desqualificado.

Da parte dos educados homens de laboratório é certamente muito forte o desejo de não terem suas argumentações físicas mescladas com fatores incomensuráveis, tais como os sentimentos. Tenho ouvido a maioria dos biólogos inteligentes dizendo: "é tempo dos homens de ciência protestarem contra o reconhecimento, na investigação científica, de uma coisa tal como a consciência”. Em síntese, sentimentos constituem a metade não-científica da experiência, e nos estudos de sua predileção qualquer um que queira chamar a si mesmo de "cientista" estará contente em comprar uma homogeneidade de termos já engatados, ao irrisório preço de admitir um dualismo que, ao mesmo tempo em que concede à consciência um status independente, bane-a para o limbo da ineficácia causal, de onde nenhuma intromissão precisa ser temida.

Essa atitude sectária insinua o dualismo epifenomenalista dos pesquisadores mecanicistas. Ao abolir a eficácia causal da consciência não se nega a existência da consciência, mas sim se estabelece uma absoluta separação entre o psíquico e o físico, e, dogmaticamente, afirma-se que o estudo científico deve se restringir apenas ao último ${ }^{5}$. James comenta que os pesquisadores de orientação fisiológica mecanicista, no intuito de definitivamente banir a consciência do campo de estudo da ciência, costumavam levantar a perene questão filosófica de como seria possível imaginar o modus operandi pelo qual o pensamento afetaria as moléculas cerebrais, de modo que fosse possível suplantar o abismo entre processos psíquicos e processos físicos. Mas James salienta que, se os fisiologistas estivessem dispostos a seriamente pensar de modo filosófico, então eles deveriam

5 Note-se que atitudes sectárias, promovidas por estudiosos da neurofisiologia, não são exclusividade da fisiologia mecanicista do século XIX. Quando deparamo-nos com argumentos reducionistas como aqueles apresentados pelo materialismo eliminativo (mesmo este não sendo dualista), ficamos estupefatos com a longevidade vigorosa do método (digamos, "ostracistóide") de banir os termos mentalistas de uma psicologia da consciência para o terreno do não-científico. 


\section{R. R. Kinouchi}

levar em conta também o ceticismo humeano acerca da causalidade (Hume, 1748/2000) e considerar que qualquer noção de causa, até entre processos absolutamente materiais, enfrenta certas dificuldades. Ou seja, os fisiologistas mecanicistas da época baseavam-se em argumentos de natureza filosófica somente quando bem lhes apetecia. Entretanto, se esqueciam de que a própria noção de causalidade mecanicista esbarrava em longevas controvérsias. É bem verdade que James considerava a abordagem fisiológica como sendo simples e coerente. Porém, ao levá-la às suas últimas consequiências, os respectivos pesquisadores esquivavam-se do árduo trabalho do estudo empírico da consciência, movidos muito mais por dogmatismo filosófico do que por sólidas bases empíricas. Ocorre que, para James (1890/1983b), a questão de se a consciência tem eficácia causal, ou não, sobre processos fisiológicos não poderia ser abandonada sem que ao menos se cogitasse tal possibilidade:

Mas a Psicologia é uma ciência natural, aceitando como seus dados certos termos de forma não-crítica, e cessando com reconstruções metafísicas. Como a Física ela deve ser ingênua [naïve]; e se, em um campo de estudo muito particular, ela encontrar que as idéias parecem [funcionar como] causas, seria melhor continuar a falar delas de tal modo (p. 141).

A partir desse ponto, James passa a se dedicar a essa possibilidade, por meio de um argumento darwinista que indicará evidências da eficácia causal da consciência.

\section{O Darwinismo Aplicado às Relações entre a Consciência e o Cérebro}

No último subtítulo do capítulo "Teoria do Autômato", James refuta a argumentação precedente e expõe seu próprio ponto de vista. Começa afirmando que a complexidade da psique humana se mostra associada ao desenvolvimento evolutivo de nossa espécie. Mas se a consciência fosse tão somente um subproduto inerte, por que ela haveria de ser selecionada durante a evolução? Para James, a consciência deve ter alguma utilidade, que por sua vez deve traduzirse em vantagens adaptativas que ajudem o organismo na luta pela sobrevivência. Caso contrário, se fosse incapaz de proporcionar vantagens adaptativas, a seleção natural de organismos mais conscientes, em detrimento daqueles que possuem consciência em menor grau, não teria explicação. Em síntese, para que consciência seja uma variável crítica no processo de evolução, ela deve efetivamente auxiliar a sobrevivência de seu detentor.

Ou seja, James entende que a consciência só poderia prestar tal auxílio se tivesse eficácia causal sobre a série de eventos fisiológicos - eficácia causal do psíquico sobre o físico. Em outros termos, se fosse capaz de influenciar decisivamente o comportamento dos organismos nas luta pela vida (struggle for existence). É nesse ponto que as idéias de Darwin (1855/1902), mostram-se claramente. Percebese que James procura naturalizar a consciência, inquirindo sobre seu valor adaptativo. Com esse movimento, tanto concebe a consciência como condicionada à evolução, bem como infere a eficácia causal dos eventos psíquicos sobre os eventos cerebrais, afastando-se tanto do espiritualismo metafísico quanto do mecanicismo fisiológico, respectivamente.

Note-se ainda que na argumentação jamesiana aparece o valor adaptativo da consciência, mas não existe menção aos custos de sua manutenção. Atualmente tem sido aceito que existe um custo metabólico nos processos ocorridos no córtex cerebral (e.g., a existência de células glia que dão suporte metabólico aos neurônios corticais, bem como a atividade registrada pelos aparelhos de brain imaging). Mas, se houver um custo sem benefício algum, então a consciência estaria gerando, na verdade, um desperdício energético; o que deveria levar à extinção de seres conscientes. Apesar de James não postular tal custo de manutenção, a existência disso apóia a linha de raciocínio jamesiana. Na época talvez se pudesse dizer que tal custo não era realmente constatado. Mas, nesse caso, o ônus da prova recairia sobre o epifenomenalismo; isto é, seria necessário provar que a consciência não tem um custo metabólico e, mais cedo ou mais tarde, isso entraria em conflito com os resultados da psicofisiologia.

Mas apenas inferir a eficácia causal da consciência não nos leva muito adiante. É preciso também que se explicite como se dá tal processo. James apresenta em seguida um dos pontos centrais de sua teoria, qual seja: que a consciência atua como uma função selecionadora das inúmeras possibilidades proporcionadas por aparato cerebral extremamente complexo. Sustentava suas inferências salientando que, indubitavelmente, o cérebro é uma estrutura muito complexa, e que os possíveis estados que esse órgão pode realizar são praticamente inumeráveis. Era também consenso que o córtex cerebral, responsável por processos altamente inteligentes, difere essencialmente das estruturas inferiores. Essas últimas realizam ações simples e invariáveis, que contribuem para a manutenção de curto prazo da vida do indivíduo. Porém, os processos complexos e conscientes são, na sua grande maioria, dirigidos para eventos futuros, muitas vezes indetermináveis no curto prazo. Para James, essa indeterminação capacita o detentor de um córtex bem desenvolvido a se adaptar às mínimas alterações das circunstâncias ambientais; de modo que um determinado processo pode ser suspenso, modificado, ou procrastinado, até que as circunstâncias tornem-se plenamente favoráveis para alcançar determinado fim. Mas, por outro lado, se adotada a posição puramente mecanicista, tal capacidade de mudança de um curso de ação ficaria em muito prejudicada. Na verdade, o automatismo mecanicista tolhe a variabilidade de ação que garantiria adaptação dentro de um meio ambiente inconstante.

Mas afinal, como a consciência influiria na adaptação do sujeito às mudanças do ambiente? Mais uma vez baseado em princípios darwinistas, argüia que a consciência inibiria processos que não estão ligados aos interesses do indivíduo, atuando como uma agência seletiva sobre as infindas possibilidades proporcionadas pelo aparato cerebral. Portanto, 
essa pressão seletiva da consciência possibilitaria, ao detentor de um cérebro capaz de inúmeras possibilidades de ação, dirigir-se a uma delas por aproximações sucessivas. Segundo James (1890/1983b):

Permita-se que a consciência seja apenas aquilo que ela parece ser para si mesma, e assim ela irá ajudar um cérebro instável a alcançar seus fins próprios. Os movimentos do cérebro per se fornecem os meios de obtenção desses fins mecanicamente, mas somente quando se afastam de outros fins, se assim podem ser chamados, que não são os próprios do animal, e freqüentemente completamente opostos. O cérebro é um instrumento de possibilidades, mas não de certezas. Se a consciência possuir eficácia causal ela irá, mediante seus próprios fins apresentados ao cérebro, e conhecendo bem as possibilidades que levam a eles, reforçar as possibilidades favoráveis e reprimir as desfavoráveis ou indiferentes. Neste caso, espera-se que as correntes nervosas, caminhando através de células e fibras, sejam fortalecidas pelo despertar da consciência em determinado curso, sendo que os outros cursos são abafados. Permanece insolúvel, para o presente momento, como uma tal reação da consciência possa ocorrer sobre as correntes nervosas; mas é o bastante para meu propósito ter mostrado que a consciência não pode ter uma existência inútil, e que o problema é bem menos simples do que os automatistas-cerebrais sustentam (pp. 144-145).

Após discorrer sobre tal uma hipótese de que ações adaptativas complexas são oriundas da seleção da consciência sobre a variação dos processos cerebrais, James procura fornecer evidências para essa hipótese, pois não bastava que sua argumentação fosse teoricamente coerente (a teoria do Autômato Consciente também o era), mas havia também a necessidade de que se encontrassem considerações empíricas que a justificassem. James (1890/1983b) então apresenta considerações empíricas que fortaleceriam sua hipótese:

Por exemplo, a consciência é mais intensa quando os processos nervosos são hesitantes. Em situações habituais, rápidas e automáticas, ela diminui-se ao mínimo. Nada poderia ser mais apropriado do que isso se a consciência tivesse eficácia causal, nada seria mais sem sentido se assim não fosse. Ações habituais são certas, e não havendo perigo de que se desviem, não necessitam ajuda alheia. Já nas situações de hesitação, aparecem diversas possibilidades de descarga nervosa final (...) Onde a indecisão é grande, como quando diante de um salto perigoso, a consciência é agonizantemente intensa. (p. 145).

Além desse dado - que a consciência mostra-se mais ativa quando existem cursos de ações diversos a serem escolhidos - é apresentada uma outra consideração que contradiz a teoria fisiológica mecanicista. É que se um processo mecânico (tal como a ação de uma máquina) sofre danos em seu aparato físico (tal como a quebra de uma peça), o processo subseqüente se desenrolará sempre de forma diversa daquela esperada, ou seja, de forma errada. Mas um cérebro que sofre algum dano, e que poderia ser comparado a uma máquina quebrada, pode, depois de algum tempo, retornar às suas funções habituais. Ora, se a consciência conseguisse ajudar a formar novas configurações de canais nervosos, que restaurassem as funções prejudicadas, o cérebro poderia voltar a exercê-las. Mas, se a consciência não tiver eficácia causal, como explicar o restabelecimento de funções danificadas? Para James, é a ação ativa da consciência que possibilita a reconstituição dessas funções danificadas, por meio da utilização de outras vias de condução capazes de contornar os danos físicos. Com o auxílio da consciência, uma mesma função poderia ser exercida de maneiras diversas pelo mesmo aparato cerebral - assim como um homem pode contornar uma montanha tanto tomando o rumo da esquerda quanto o da direita, se lhe for impossível transpô-la por cima. A hipótese de James é ainda atual, pois, não fala em reconstituição dos tecidos danificados, mas sim em reconstituição de funções. Embora possa haver controvérsias acerca da capacidade de regeneração do tecido cerebral, e mesmo sobre a criação de novas ligações sinápticas na idade adulta, há consenso clínico sobre a possibilidade de restauração de funções por meio de intervenções terapêuticas.

\section{Herbert Spencer e sua Teoria Evolucionária}

Embora o darwinismo, aplicado no contexto da fisiologia, pudesse legar ao indivíduo um espaço de ação consciente e voluntária, James buscava mais evidências contra o determinismo que informava o mainstream da ciência da época. Um assunto central no qual o determinismo vinha sendo aplicado era na formulação de teorias da evolução. A bem da verdade, é preciso assinalar que, em meados do século XIX, o evolucionismo não era uma idéia de todo original. Atualmente pode parecer que Charles Darwin não tivesse concorrentes diretos, como se tudo que concerne ao conceito de evolução fosse de sua autoria - o que não é de todo certo, pois que A. R. Wallace pode ser considerado praticamente como co-descobridor da seleção natural (cf. Horta, 2003). No entanto, a concepção de que os seres vivos evoluíram ao longo das eras tinha defensores desde muito antes. Na época de Darwin, a questão mais urgente era explicar como funcionavam os mecanismos dessa evolução; trabalho ao qual dedicara-se também, por exemplo, o naturalista francês Jean Lamarck (1744-1829). O filósofo evolucionista britânico Herbert Spencer também empreendera a tarefa de encontrar tais mecanismos, mas de tal modo que fosse possível aplicá-los não só à biologia, incluindo desde a formação do universo até a evolução da moral e da estética. Sua abrangente teoria evolucionária era uma forte concorrente do darwinismo. Spencer se baseava prioritariamente em princípios lamarckianos, como a concepção de que hábitos adquiridos por um indivíduo poderiam produzir adaptações congênitas em seus descendentes (mais adiante ficará claro que, em razão desse pressuposto, sua teoria acabava por se mostrar determinista, e ainda por cima racista). Aliás, Darwin também iniciara sua abordagem por essa via 
(a da adaptação congênita), abandonando-a gradualmente a partir de 1838, porém sem negá-la por completo. Já Spencer era essencialmente lamarckiano, divergindo do Darwin de $A$ Origem das Espécies. Contudo, é preciso informar que, no spencerianismo, também há espaço para um conceito análogo à seleção natural, denominado de equilibração indireta. Ao se comparar Spencer com Darwin, não se deve pensar que eles fossem inimigos (ver Dennett, 1998) ${ }^{6}$. As diferenças referem-se mais ao grau de utilização do lamarckismo: baixo em Darwin e destacado em Spencer.

James (1890/1983b) admite que o trabalho de Spencer tivesse algum valor, pois, por se tratar de uma abordagem evolucionista, ao menos o spencerianismo era uma alternativa melhor do que uma psicologia puramente racional:

\begin{abstract}
Até um certo estágio de desenvolvimento de uma ciência, um certo grau de indefinição é o que há de melhor para sua fertilidade. No geral, poucas fórmulas recentes têm feito um maior real serviço, conquanto incompleto, do que o spencerianismo, segundo o qual a essência da vida mental e corporal é, a saber, "o ajustamento de relações internas às externas". Tal fórmula é a vagueza encarnada; mas por levar em conta o fato de que a consciência habita o ambiente, que age sobre o ambiente, e que por sua vez o ambiente reage; sendo breve, na medida em que o spencerianismo toma a consciência em meio a todas as suas relações concretas, isso faz com que tal teoria seja imensamente mais fértil do que a antiquada "psicologia racional", que tratou a alma como um ente separado, suficiente em si mesmo, considerada apenas em suas propriedades e natureza (James, 1890/1983b, p. 19).
\end{abstract}

De acordo com a teoria spenceriana a "vida é um contínuo ajustamento de relações internas às relações externas" (Spencer, citado por James, 1890/1983, p.19). Essas relações externas se dão pela experiência, mais especificamente pela ordem e frequiência das impressões recebidas pelo sujeito. Por sua vez, a mente do indivíduo copiaria as ordens de seqüências e coexistências, de maneira que as imagens das coisas, internamente, tornar-se-iam assemelhadas às coisas externas propriamente ditas. Para impressões constantes entre si ocorrem conjunções constantes de idéias; para impressões fortuitas ocorrem conjunções casuais de idéias. Em síntese, as relações internas espelham relações externas.

Essa perspectiva, centrada na experiência, alinha-se bem com a tradição do empirismo inglês, e adiciona um fator evolucionário quando aceita que, durante a filogênese, as experiências mais freqüentes vividas pelos organismos, tais como as relações espaço-temporais, tornam-se de alguma forma hereditárias. Isto é, o argumento torna-se evolucionário quando admite que as inumeráveis experiências dos antepassados de uma raça possam vir a ser congênitas na descendência (lamarckismo). Aqui, recorrer

6 De acordo com Dennett (1998), Spencer era um entusiasmado defensor das idéias de Darwin, mesmo que por vezes a utilizasse equivocadamente, e chegasse a conclusões diversas daquelas propostas por Darwin. a uma passagem do próprio Spencer será um procedimento bastante elucidativo:

A lei universal de que, mantidas outras coisas constantes, a coesão de estados psíquicos é proporcional à freqüência com que eles seguiram uns aos outros na experiência, fornece uma explicação para as assim denominadas "formas de pensamento", tão logo seja ela complementada pela lei de que sucessões psíquicas habituais acarretam alguma tendência hereditária para tais sucessões, as quais, sob condições persistentes, irão tornar-se cumulativas de geração para geração. Vemos que o estabelecimento daquelas ações reflexas compostas chamadas de instintos é assim compreensível mediante o princípio de que as relações internas são, pela perpétua repetição, organizadas em correspondência com as relações externas. Também devemos observar que o estabelecimento de relações mentais instintivas, consolidadas e indissolúveis, constituintes de nossas idéias de Espaço e Tempo são compreensíveis pelo mesmo princípio (...) A organização das relações subjetivas ajustadas àquelas relações objetivas tem sido cumulativa, não apenas em cada raça de criatura, mas em todas as sucessivas raças de criaturas; e tais relações subjetivas têm, portanto, se tornado mais consolidadas do que qualquer outra (...) Sendo [Espaço e Tempo] os elementos do pensamento mais constantes e infinitamente repetidos, eles devem tornar-se elementos automáticos do pensamento - os elementos impossíveis de serem descartados - as "formas de intuição" (Spencer, citado por James 1890/1983b, p. 1219).

Por essa via, Spencer conciliava suas idéias com certos aspectos da doutrina kantiana sobre o Espaço e o Tempo (Kant, 1781/1999). As formas da intuição seriam aqueles tipos de experiência mais frequientes do que quaisquer outras. E sua universalidade se deveria ao fato de que os organismos atuais estão congenitamente ajustados a tais relações exteriores espaço-temporais. Já no que tange relações contingentes - isto é, não necessárias, no linguajar da lógica formal - Spencer achava que quando o meio ambiente exterior de um organismo altera-se, esse organismo naturalmente procura alterar seu próprio comportamento, com o intuito de restabelecer o seu devido ajustamento às novas condições. Essas alterações, por sua vez, engendrariam novas configurações anatômicas. Spencer denominou equilibração direta a esse mecanismo pelo qual os organismos adaptam-se às alterações do meio externo, evidentemente seguindo princípios tipicamente lamarckianos. Richards (1982) comenta que na teoria de Spencer "o principal mecanismo de evolução era a internalização de relações externas, e que esse mecanismo progressivamente compeliu as formas anatômicas e as estruturas mentais pouco generalizadas a se tornarem correspondências mais definidas com o ambiente" (p.400).

Além da equilibração direta, Spencer afirmava que um segundo mecanismo colabora no processo de evolução dos seres vivos. De forma breve, se variações acidentais favorecerem a adequação das relações internas dos indivíduos às relações exteriores do ambiente, então essas variações 
acidentais serão selecionadas - algo muito semelhante ao que Darwin defendia. Spencer denominou esse mecanismo como equilibração indireta, concedendo-lhe, no entanto, importância menor.

Já expusemos que, para James, embora o spencerianismo fosse equivocado, havia nele algum mérito, pois levava em conta a evolução dos organismos e suas relações com o meio ambiente. Ressalvado o valor disso, agora é necessário mostrar as razões que o levaram a criticar Spencer, às vezes de forma bastante áspera.

\section{Objeções ao Determinismo na Evolução Sociocultural}

As críticas de James a Spencer se referem a questões socioculturais engendradas numa concepção determinista de evolução. Isso porque, admitindo-se o spencerianismo, e sua ênfase sobre a idéia de equilibração direta, deve-se também aceitar que, durante a evolução, o ambiente externo moldou coercitivamente as características e as capacidades das várias etnias humanas. Para que se mantenha a consistência do argumento, é preciso admitir que aqueles indivíduos de uma etnia que apresentaram capacidades excepcionais, e que por sua vez produziram pensamentos que mudaram a história da humanidade, conseqüentemente também foram determinados por fatores hereditários. Por exemplo, Spencer afirma que:

Segue do argumento geral o corolário de que o cérebro humano é um registro de um sem-número de experiências recebidas $d u$ rante a evolução da vida, mais precisamente durante a evolução das séries de organismos aos quais o organismo humano tem estado ligado. Os efeitos das experiências mais uniformes e freqüentes nos têm sido legados, e vagarosamente somam-se sobre aquela alta inteligência que subjaz latente no cérebro da criança - a qual a criança quando em vida exercita ou fortalece - e que, com uma mínima adição, será legada às gerações futuras. E assim acontece ao Europeu herdar de 20 a 30 polegadas quadradas de cérebro a mais que o habitante de Papua. Assim acontece que faculdades, tais como a música, que escassamente existem em algumas raças inferiores, vêm a ser congênitas nas raças superiores. Isso explica porque é que, longe dos selvagens que não conseguem contar os dedos, falantes de uma linguagem constituída apenas de nomes e verbos, surgem finalmente nossos Newtons e Shakespeares. (Spencer, citado por James, 1890/1983b, p. 1222).

Ora, vê-se claramente quão conveniente, para britânicos, é o empirismo evolucionário de Spencer quando aplicado à sociologia. James considera falso tal argumento. Quando afirma que Shakespeare e Newton são descendentes de uma raça mais avançada, e que por isso possuem habilidades mais desenvolvidas, Spencer destaca a filogênese em detrimento da ontogênese. Assim sendo, pouco haveria de individualmente original na obra desses grandes pensadores. Eles seriam apenas a conseqüência natural das experi- ências passadas de sua raça, um produto da superioridade racial anglo-saxônica. James não aceitava tal concepção, pois achava o gênio deveria ser entendido como um agente independente, ativo e transformador. Essa sua visão do papel ativo do gênio na evolução humana foi inspirada pelas idéias de seu padrinho, o não menos importante pensador norte-americano Ralph Waldo Emerson (1803-1882). Segundo Richards (1982): "Contra esse abstrato, que para James era um relato evolucionário moralmente detestável, ele enfatizava o que acreditava ser, por via emersoniana, a evidência histórica de que a evolução social é devida ao trabalho dos grandes líderes de uma sociedade" (p. 405).

James (1880/1992) opunha-se ao determinismo sociocultural, por acreditar que era preciso distinguir entre as causas que originam um fenômeno e as causas que o preservam. Para ele, um dos méritos do darwinismo residia exatamente no fato de que o conceito de variação acidental responde pelas primeiras (causas da origem) e a seleção natural pelas segundas (causas da preservação). No contexto da evolução sociocultural, James acreditava que o darwinismo poderia ser aplicado do seguinte modo: o gênio deveria ser tomado como uma fonte de variação dentro do tecido social. Quando as idéias do gênio encontram aceitação no ambiente social, passam a gerar um novo modo de existência; mas se o ambiente social mostra-se hostil, então as idéias e seu proponente são rejeitados, não promovendo mudança alguma, ou, no máximo, muito aquém do possível.

Rejeitado ou não pelo ambiente social, o gênio tem um papel ativo nas transformações. Ele é a fonte das variações das idéias, não sendo, portanto, um mero receptáculo das experiências passadas de sua raça. Note o leitor que, embora as críticas agora discutidas refiram-se ao evolucionismo sociocultural determinista, retorna o argumento de que o cérebro (por sua organização extremamente complexa) é a fonte das variações, e de que a consciência seria a agência que selecionaria um dos possíveis processos neurais em detrimento dos demais processos concorrentes. Nesse ponto articulam-se as discussões de natureza fisiológica, apresentadas anteriormente, com questões de âmbito epistemológico e sociológico mais geral. No Princípios de Psicologia, especificamente no capítulo "Verdades necessárias e os efeitos da experiência," James (1890/1983b) apresenta sua concepção acerca da criação de importantes teorias científicas:

Toda concepção científica é, antes de qualquer coisa, uma variação espontânea no cérebro de alguém. Para cada concepção que se prove útil e aplicável, existem milhares de outras que perecem devido sua falta de valor. Sua gênese é estritamente aparentada com aquelas inspirações poéticas, ou com as máximas de sabedoria, das quais as variações cerebrais também são a fonte. Mas enquanto a poesia e a sabedoria (como a ciência dos antigos) são sua própria razão de ser, e não vão muito além disso, as concepções científicas devem provar seu valor sendo verificáveis. Tal teste é a causa de sua preservação, não de sua produção (pp. 1232-1233). 


\section{R. R. Kinouchi}

Nessa passagem fica claro como James aplica o darwinismo sobre a gênese de idéias científicas. Para ele, essas últimas originam-se na variação das idéias no cérebro do cientista, evidenciando quão ativo e transformador é o seu trabalho. O fundamental é que os testes, aos quais as concepções científicas são submetidas, são condições de sua preservação, não de sua origem. Na verdade, a gênese das teorias científicas está na variação dos processos nos cérebros dos cientistas. O darwinismo, no entender de James, tem o mérito de separar essas duas esferas de causalidade (origem e preservação); enquanto que o spencerianismo, com sua ênfase somente na passividade do ajustamento das relações interiores às exteriores, releva o papel ativo dos cientistas na produção do conhecimento.

\section{Conclusões}

Formado em Medicina, e a par das descobertas da Fisiologia de sua época, James considerava que o mecanicismo fisiológico era coerente; no entanto, via na teoria do autômato consciente, digamos, apenas meia verdade. De certo existem leis mecânicas no que concerne o aparato cerebral, mas é preciso também considerar a possibilidade de que haja eficácia causal da consciência sobre a série de eventos fisiológicos. Além disso, naquela época vigorava uma forte tendência determinista acerca da evolução, representada pela teoria spenceriana. James discordava desse tipo de abordagem evolucionária, particularmente em razão das pressuposições ético-morais engendradas por um determinismo sociocultural.

O eixo comum das considerações jamesianas consiste na aceitação do evolucionismo darwinista, que se baseia nos conceitos de variação acidental e seleção. Em resumo, "de acordo com a nova e influente teoria evolucionária, James achava que o comportamento do homem e, em especial, a sua mente, deve ter alguma função para que a sus sobrevivência se justifique" (Marx \& Hillix, 1978, p.193). Foi essa perspectiva que capacitou James a defender que a consciência, embora condicionada pela história natural, poderia influenciar decisivamente as ações dos indivíduos. A consciência teria a função de selecionar certos cursos de ação dentre as inúmeras possibilidades oferecidas por um aparato cerebral complexo (Kinouchi, 2001).

A psicologia jamesiana, ao inferir a eficácia causal da consciência, fundamenta uma perspectiva distinta da neurofisiologia mecanicista européia de então. O darwinismo, tal como James o entendia, também fornecia o devido mérito aos grandes gênios que construíram a história humana, já que suas idéias e ações são consideradas como sendo variações selecionadas devido ao seu valor para a humanidade, e não apenas como consequiências de uma pretensa superioridade racial. Tal ênfase sobre o papel do indivíduo, que por sinal é algo típico do pensamento norte-americano, encon- tra indubitável expressão na psicologia jamesiana, a qual, como mostrado, baseava-se nas idéias de Darwin.

\section{Referências}

Darwin, C. (1902). The origin of species. London: John Murray, Albemarle Street. (Trabalho original publicado em 1855)

Dennett, D. (1998). A perigosa idéia de Darwin. (T. M. Rodrigues, Trad.) Rio de Janeiro: Editora Rocco.

Descartes, R. (1999). As paixões da alma. (E. Corvisieri, Trad.). Em J. Florido (Org.), Os Pensadores: Descartes (pp. 101-232). São Paulo: Editora Nova Cultural. (Trabalho original publicado em 1649)

Flanagan, O. (1997). Consciousness as a pragmatist viwes it. Em R. A. Putnam (Org.), The Cambridge Companion to William James (pp. 25-48). New York: Cambridge University Press.

Harrison, S. (2004). Was James a redutionist? Streams of William James, 6(3), 19-24.

Herrnstein, R. J. \& Boring, E. G. (Org.) (1971). Textos básicos de História da Psicologia. São Paulo: Herder e EDUSP.

Horta, M. R. (2003). O impacto do manuscrito de Wallace de 1858. Scientiae Studia, 1(2), 217-229.

Hume, D. (2000). Investigação acerca do entendimento humano. (A. Aiex, Trad.) Em J. Florido (Org.), Os Pensadores: Hume (pp. 17-154). São Paulo: Editora Nova Cultural. (Trabalho original publicado em 1748)

James, W. (1983a). Are we automata? Em I. Skruspkelis, I. (Org.), The Works of William James: Essays in Psychology. Cambridge: Harvard University Press. (Trabalho original publicado em 1878)

James, W. (1983b). The Principles of Psychology. Cambridge: Harvard University Press. (Trabalho original publicado em 1890)

James, W. (1992). Great Men and Their Environment. Em G. E. Myers (Org.), William James Writings 1878-1899 (pp. 618-646). New York: Literary Classics of United States.

Kant, I. (1999). Crítica da Razão Pura. (V. Rohden \& U. B. Moosburger, Trad.). Em J. Florido (Org.), Os Pensadores: Kant. São Paulo: Editora Nova Cultural. (Trabalho original publicado em 1781)

Kinouchi, R. R. (2001). Surmounting Rationalism and Associationism Controversies. Streams of William James, 3(2), 1-4.

Kinouchi, R. R. (2004). Ainda existe consciência? Scientiae Studia, 2(3), 415-425.

Marx, M. H. \& Hillix, W. A. (1978). Sistemas e Teorias em Psicologia. São Paulo: Editora Cultrix.

Richards, R. J. (1982). The Personal Equation in Science: William James's Psychological and Moral Uses of Darwinian Theory. Em K. E. Carpenter (Org.), A William James Renaissance: Four essays by Young Scholars (pp. 387-425). Boston: Harvard Library Bulletin.

Recebido em 31.10.2005

Primeira decisão editorial em 06.04.2006

Versão final em 21.06.2006

Aceito em 04.08.2006 